\title{
Féeries
}

Études sur le conte merveilleuX, XVII $-\mathrm{XIX}{ }^{\mathrm{e}}$ siècle

\section{Sophie Raynard, La Seconde préciosité. Floraison des conteuses de 1690 à 1756}

Gunter Narr Verlag Tübingen, 2002, Biblio 17-130

\section{Anne Defrance}

\section{OpenEdition}

\section{Journals}

Édition électronique

URL : http://journals.openedition.org/feeries/135

DOI : $10.4000 /$ feeries. 135

ISSN : 1957-7753

\section{Éditeur}

UGA Éditions/Université Grenoble Alpes

\section{Édition imprimée}

Date de publication : 1 février 2005

Pagination : 314-318

ISBN : 2-84310062-3

ISSN : 1766-2842

\section{Référence électronique}

Anne Defrance, « Sophie Raynard, La Seconde préciosité. Floraison des conteuses de 1690 à 1756 », Féeries [En ligne], 2 | 2005, mis en ligne le 31 janvier 2007, consulté le 22 septembre 2020. URL : http:// journals.openedition.org/feeries/135; DOI : https://doi.org/10.4000/feeries.135

Ce document a été généré automatiquement le 22 septembre 2020.

(c) Féeries 


\section{Sophie Raynard, La Seconde préciosité. Floraison des conteuses de 1690 à 1756}

Gunter Narr Verlag Tübingen, 2002, Biblio 17-130

\section{Anne Defrance}

1 Les catégories esthétiques de galanterie, préciosité, baroque, classicisme, sont, depuis quelque temps, en pleine redéfinition. Dans le débat sur la préciosité, deux courants critiques fortement opposés se sont fait jour ces quatre dernières décennies, déterminant des pôles et des tendances entre lesquels divers critiques se positionnent. Certains d'entre eux, à la suite de Roger Lathuillère, voient dans la préciosité une catégorie essentielle au XVII ${ }^{\mathrm{e}}$ siècle, et à plusieurs égards puisqu'ils affirment qu'elle aurait inspiré les plus grands écrivains dans tous les genres (poésie, roman, théâtre) et que, "située au centre du siècle, elle en reflète de nombreux aspects, soit qu'elle résume ceux qui la précèdent, soit qu'elle prépare et annonce ceux qui relèveront d'elle » (Roger Lathuillère, La Préciosité, Droz, 1966). Pour lui comme pour les critiques qui se rangent de manière plus ou moins nuancée derrière cette conception (Myriam Maître, Philippe Sellier...), il y a bien eu des précieuses, mais la préciosité a été l'objet d'une entreprise de dénigrement et elle subit, depuis le XVII siècle, l'image négative que Molière, entre autres, lui a assignée ; elle mérite donc d'être réhabilitée.

2 À l'opposé de cette vision, Jean-Michel Pelouz, Roger Duchêne estiment que la préciosité est une reconstruction a posteriori (le substantif n'existait d'ailleurs pas à l'époque), une « invention commode qui a permis à la société galante de caricaturer ses propres défauts» (J.M. Pelouz, Amour précieux, amour galant, [1654-1685], Essai sur la représentation de l'amour dans la littérature et la société mondaine, Klincksieck, 1980). Delphine Denis, tout en reconnaissant une certaine utilité à la catégorie, trouve davantage opératoire celle de la "galanterie », catégorie naissant dans les années 1660. (Entre ses divers travaux, signalons son dernier ouvrage, Le Parnasse galant. Constitution d'une catégorie littéraire au XVII siècle, Champion, 2001). Parmi les nouvelles études sur la galanterie, signalons également les travaux d'Eric Méchoulan (Le Corps imprimé, 
Montréal, Balzac, 1999), Emmanuelle Morgat (Naissance de l'histoire littéraire française, les représentations aux XVII et XVIII' siècles de l'histoire des lettres de langue française, Thèse Paris III, sous la direction d'Alain Viala, 1996).

L'ouvrage de Sophie Raynard dont il est ici question est la version publiée de sa thèse soutenue en 1999 à Paris IV, sous la direction de Philippe Sellier : Tradition précieuse et représentation du féminin dans les contes de Charles Perrault à Madame Leprince de Beaumont. L'auteur n'hésite pas à éliminer d'emblée tout un pan de la critique contemporaine : "D'une manière générale, la critique d'aujourd'hui se range sur [le] sujet [de la préciosité] dans la lignée des travaux d'Antoine Adam et de Roger Lathuillère » (p. 25). Elle se situe on ne peut plus clairement de leur côté : «c'est dans cette lignée que nous allons nous placer parce que ce sont les chercheurs qui ont réfléchi le plus sur les méthodes d'approche de la préciosité afin de tomber dans le piège des idées reçues et dans le manque de rigueur d'analyse » (p. 25). Elle déplore la "gêne ", la prudence ou même la « fausse modestie » (p. 15) dont se sont encombré des critiques comme Jacques Barchilon ou Myriam Maître (plusieurs fois citée mais oubliée de la bibliographie), au moment où ils présentent, dans le début de leurs ouvrages, leurs objets d'étude : les contes de fées pour l'un, les précieuses pour l'autre (notons que dans les passages cités, ils faisaient alors précisément état du dénigrement que ces mêmes objets avaient subi de la part de la critique). Sophie Raynard annonce qu'à leur différence, «c'est la tête haute qu'“[elle va] s'engager dans cette voie de la préciosité, tant [elle] sent l'intérêt d'une telle étude pour l'histoire littéraire et idéologique" ». Aussi poursuit-elle : «D'un point de vue féministe, l'apport est indéniable et nous souhaitons le montrer sans avoir recours à la polémique ou à l'outrecuidance. Quoi de plus valorisant en effet pour le "sexe faible" que de manifester qu'au XVII siècle de fortes personnalités féminines ont su se faire entendre? » (p. 14)...

4 S'appuyant sur la classification des contes de fées proposée par Jacques Barchilon (tendance classique, magique-orientale, fantastique, magique-licencieuse), l'auteur annonce qu'elle entend montrer que la tendance classique (représentée, selon Barchilon, par les imitateurs de Perrault et de Mme d'Aulnoy: Mme de Lintot, Mlle de Lubert, Caylus et Pajon) «est en fait, en ce qui concerne les femmes, une tendance précieuse » (p. 18), alors qu'un auteur comme Perrault s'en distingue. Quant au choix de son corpus (le conte de fées féminin de la fin du XvII siècle jusqu'à Mme Leprince de Beaumont), elle l'explique ainsi dans son introduction: «nous proposons un corpus de femmes parce qu'il est net que ce sont elles qui ont véhiculé la préciosité en réactivant le genre féerique » (p. 19). Pour tenter de justifier davantage cette limite, elle renvoie à la simple mention d'un article de Barchilon: l'épuration du style et la brièveté de Mme Leprince de Beaumont par rapport à Mme de Villeneuve suffirait, selon elle, à montrer que Mme Leprince de Beaumont est à la charnière « entre la préciosité de ses consœurs et la volonté d'utiliser ce genre particulier à des fins moralisantes pédagogiques, tout comme le firent son prédécesseur Perrault et ses contemporains du XVIII siècle » (p. 20). Il faudra donc attendre la suite de l'ouvrage pour que le lecteur puisse espérer voir définies ces catégories, éclaircies ces superpositions notionnelles et génériques (au double sens du terme).

Dans une première partie, Sophie Raynard redéfinit la préciosité, afin de décrire «le contexte des contes de fées littéraires » (Elle évoque tour à tour la vie des conteuses, en se référant abondamment, entre autres, au livre d'Elizabeth Storer.) Dans la seconde, elle procède à l'analyse stylistique des contes féminins, afin de justifier leur 
appartenance à la tradition précieuse, par contraste avec ceux de Perrault. Elle étudie alors le style précieux, le traitement du merveilleux, la logique narrative des contes, les valeurs des uns et des autres; elle oppose les valeurs «anti-précieuses» de Perrault aux valeurs précieuses des conteuses, affirmant que chez Perrault l'amour est une "quantité négligeable », chez les conteuses un « refrain préféré » (ce sont ses soustitres). Dans la troisième partie, elle étend sa réflexion aux liens entre féminité et préciosité en littérature. Enfin, dans la dernière, elle dégage le message féministe des contes dont elle entend montrer la modernité.

En conclusion, l'auteur (après bien d'autres), évoque les raisons qui peuvent expliquer que la critique a longtemps relégué les contes de fées féminins derrière ceux de l'académicien, mais surtout elle réaffirme que c'est « dans leur différence par rapport aux textes de Perrault que réside pour [elle] leur intérêt socio-littéraire » (p.473), intérêt qui tient, à ses yeux, dans le message féministe délivré par les conteuses « du fait de leur appartenance à la tradition précieuse » (id.)

7 Vu le développement et le renouveau des études portant sur le conte de fées (études que la bibliographie rapporte partiellement), on s'étonne, à l'orée de ce travail, d'entendre encore aujourd'hui formuler le projet de convaincre « une fois pour toutes que Perrault ne doit plus être la référence ultime en matière de contes de fées » (p. 20). Était-ce nécessaire? (Mais il est vrai que bien des travaux critiques récents et novateurs sont ici passés sous silence.) Cette prétention est d'autant plus étonnante que l'auteur évoque un certain nombre de critiques féministes américains et qu'elle utilise le livre de Raymonde Robert qui, couvrant plus d'un siècle de la production féerique, dispenserait à lui seul de telles redites (Sophie Raynard reproduit d'ailleurs l'un de ses tableaux en fin de volume et la cite longuement). Pourquoi donc avoir choisi, pour étudier une production de contes féminins qui s'étend sur plus d'un demi-siècle, de les comparer à ceux du seul Perrault, encore et toujours lui, Perrault dont la valeur référentielle et l'originalité s'en trouvent de ce fait plus que jamais affirmée, a contrario des déclarations d'intention inaugurales de l'auteur? Peut-on, en conclusion, estimer avoir détrôné Perrault en disant avoir prouvé que «le bon goût n'est pas forcément toujours caractéristique de son style, du fait du caractère gaulois de certains de ces contes» (p.472) ? Est-ce, surtout, légitime d'avoir privilégié cette unique référence masculine, quand on travaille sur une période de plusieurs décennies, laissant de côté les Nodot, Mailly, Préchac, Caylus, etc., sans s'en expliquer de manière convaincante et alors que ce dernier, pour n'évoquer que ce seul auteur, revendique pourtant le modèle d'une Mme d'Aulnoy et que, plus généralement, bien des contes masculins n'auraient pu être taxés aussi facilement des « défauts » qu'on reproche ici à Perrault ? Les contes masculins ne célèbrent-ils pas, eux aussi, les valeurs amoureuses? Pour l'auteur, la différence de fond entre les contes masculins et féminins est indéniable, et elle le réaffirme en fin de parcours: "la différence d'écriture [...] est due à une différence d'éducation des deux sexes et aux rôles distincts que la société leur a assignés ». On peut souscrire à une telle explication, mais l'auteur poursuit en disant qu' ' il y a aussi une différence radicale de forme parce que la préciosité était par définition un courant féminin" (p. 475). Cette assertion tautologique ne dispense pas que nous puissions toujours nous poser cette question, à l'issue de notre lecture : les critères stylistiques et idéologiques dégagés ici pour caractériser la préciosité étaient-ils uniquement applicables aux seules productions féminines ? Est-ce, au bout du compte, une catégorie suffisamment productive pour rendre compte des traits communs d'une production 
aussi diverse, en laissant dans l'ombre autant d'auteurs pour n'en retenir qu'un seul sur une aussi longue période? 